\title{
Developmental Changes in Eye-Blink Conditioning and Neuronal Activity in the Cerebellar Interpositus Nucleus
}

\author{
John H. Freeman Jr and Daniel A. Nicholson \\ Department of Psychology, University of lowa, lowa City, lowa 52242
}

Neuronal activity was recorded in the cerebellar interpositus nucleus in infant rats during classical conditioning of the eyeblink response. The percentage and amplitude of eye-blink conditioned responses increased as a function of postnatal age. Learning-specific neuronal activity in the cerebellum emerged ontogenetically in parallel with the eye-blink conditioned response. There were also age-specific changes in neuronal activity after the onset of the conditioned and unconditioned stimuli. The results indicate that the development of the

Developmental changes in the neural mechanisms of learning have been examined extensively in the Aplysia californica (Nolen et al., 1987; Nolen and Carew, 1988; Carew, 1989; Marcus and Carew, 1998). In contrast, very little information exists concerning developmental changes in the neural mechanisms of learning in mammals. Studies of learning in developing mammals have revealed correlations between the ontogeny of particular learned responses and the time course of anatomical maturation of the brain structures that are known to subserve these learned responses in adults (Diamond, 1990; Freeman and Stanton, 1991; Green and Stanton, 1989; Stanton et al., 1992; Rudy, 1992). However, a detailed analysis of the link between the physiological development of the brain and the ontogeny of learning in mammals has not been conducted.

Classical conditioning of the eye-blink response in infant rats has been used as a model behavioral preparation for examining the relationship between neural maturation and the ontogeny of associative learning (Stanton et al., 1992; Stanton and Freeman, 1994, 1999). An advantage of using eye-blink conditioning as a developmental model preparation is that the essential neural circuitry underlying the conditioned response (CR) has been characterized extensively (Lavond et al., 1993; Thompson and Krupa, 1994; Steinmetz, 1998). The parameters that influence the rate and strength of eye-blink conditioning have also been characterized extensively (Gormezano et al., 1962, 1983; Gormezano, 1966).

The cerebellum is an essential component of the neural circuitry underlying the eye-blink conditioned response in adult organisms. Lesions or inactivation of the cerebellar deep nuclei prevented acquisition and retention of the eye-blink CR (McCormick et al., 1982; Clark et al., 1984; Yeo et al., 1985; Krupa et al.,

\footnotetext{
Received Aug. 11, 1999; revised Oct. 5, 1999; accepted Oct. 29, 1999.

We thank Dr. Mark E. Stanton and the United States Environmental Protection Agency for loaning the eye-blink conditioning equipment to J.H.F. We also thank Dr. Jeremy Payne for the neuronal spike separation and analysis software.

Correspondence should be addressed to John H. Freeman, Department of Psychology, University of Iowa, Seashore Hall, Iowa City, IA 52242. E-mail: johnfreeman@uiowa.edu.

Copyright (C) 2000 Society for Neuroscience $\quad 0270-6474 / 00 / 200813-07 \$ 15.00 / 0$
}

eye-blink conditioned response may depend on the development of stimulus-evoked neuronal responses and learningspecific plasticity in the cerebellum. Functional immaturity in the afferent neural pathways may limit the induction of neural plasticity in the cerebellum and thereby limit the development of the eye-blink conditioned response.

Key words: ontogeny; cerebellum; interpositus; learning; conditioning; eye-blink

1993). Extracellular recordings of neuronal activity within the cerebellar cortex and deep nuclei showed that a large proportion of cerebellar neurons exhibit conditioning-related increases in firing before the onset of the unconditioned stimulus (US) (McCormick and Thompson, 1984; Berthier and Moore, 1986, 1990; Gould and Steinmetz, 1994, 1996). Moreover, Schreurs and colleagues demonstrated learning-specific increases in cerebellar neuronal membrane excitability after eye-blink conditioning (Schreurs et al., 1991, 1997, 1998). These findings are consistent with the hypothesis that acquisition of the eye-blink conditioned response in adult organisms depends on the induction of neuronal plasticity within the cerebellum.

Developmental changes in cerebellar function could play a pivotal role in the ontogeny of eye-blink conditioning. Rodents and humans exhibit extensive postnatal anatomical maturation of the cerebellum (Berry and Bradley, 1976; Altman, 1982; Anderson and Flumerfelt, 1985), and physiological studies of rat cerebellar neuronal development demonstrated significant functional changes during the first few postnatal weeks (Crepel, 1971, 1972, 1974; Crepel et al., 1976; Puro and Woodward, 1977a,b; Gardette et al., 1985a,b; Crepel and Penit-Soria, 1986). The developmental changes in cerebellar physiology may critically influence the capacity to induce and maintain learning-specific plasticity.

This report describes the results of our initial examination of neuronal activity in the cerebellar deep nuclei of infant rats during eye-blink conditioning. The primary goal of this study was to characterize developmental changes in stimulus-evoked and learning-related neuronal activity in the cerebellar interpositus nucleus.

\section{MATERIALS AND METHODS}

Subjects. The subjects were 16 Long-Evans rat pups. Littermates were trained on either postnatal day 17 (P17) and P18 $(n=8)$ or P24 and P25 $(n=8)$. The rats were housed in the animal colony in Spence Laboratories at the University of Iowa. All rats were maintained on a $12 \mathrm{hr}$ light/dark photoperiod, with light onset at 6:30 A.M.

Surgery. The rat pups were given intraperitoneal injections of ketamine $(60 \mathrm{mg} / \mathrm{kg})$ and xylazine $(7.5 \mathrm{mg} / \mathrm{kg})$ for anesthesia. The rat's head was positioned in an infant stereotaxic head holder and aligned in three planes to bring it into the orientation required for placement of the 
Figure 1. Mean \pm SEM percentage of conditioned responses (left) from rat pups trained on postnatal days 17-18 (black circles) and postnatal days 24-25 (white circles) across six training sessions ( $P T$, pretraining; $*$ indicates significant group differences). The right displays representative eyelid EMG conditioned responses from rats trained on postnatal days 18 (top trace) and 25 (bottom trace). Calibration: $100 \mathrm{msec}$. Arrowheads indicate the onset of the CS and the US. PND, Postnatal day.

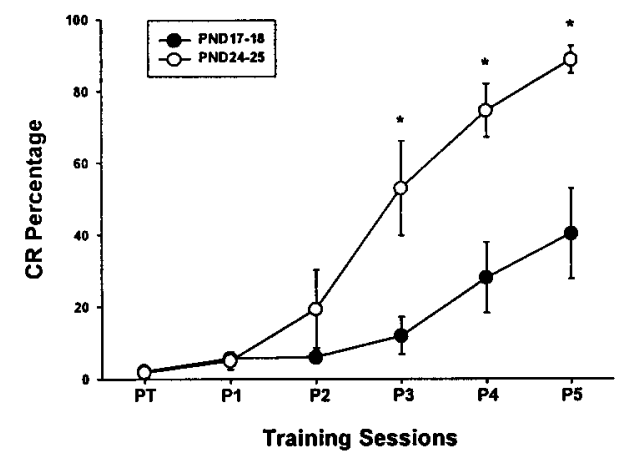

PND17-18
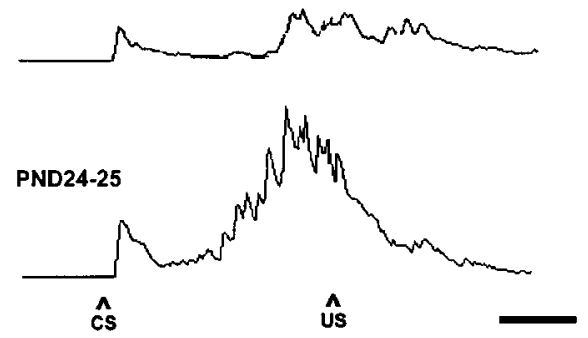

electrodes. The rats were fitted with differential EMG electrodes that were implanted in the left eyelid muscle (orbicularis oculi), and a ground electrode was attached to a stainless steel skull hook. The EMG electrode leads terminated in gold pins in a plastic connector, which was secured to the skull with dental acrylic. A bipolar stimulating electrode (for delivering the shock US) was implanted subdermally, immediately caudal to the left eye. The bipolar electrode terminated in a plastic connector that was secured to the skull by dental acrylic.

Eight insulated stainless steel electrodes $(25 \mu \mathrm{m})$ were implanted in the left interpositus nucleus of each rat under stereotaxic guidance. The stereotaxic coordinates for the interpositus nucleus were taken from lambda (anteroposterior, $-2.3 \mathrm{~mm}$, mediolateral, $+2.0 \mathrm{~mm}$, and dorsoventral, $-4.8 \mathrm{~mm}$ ). The electrodes were held in place by a microelectrode connector and dental acrylic applied to the skull. The surgical site was closed with sutures on both sides of the electrode plug. The connectors for the EMG electrodes, bipolar stimulating electrode, and microwire electrodes were connected to lightweight cables that allowed the rats to move freely during conditioning.

Conditioning apparatus. The conditioning apparatus consisted of an electrically shielded small-animal sound attenuation chamber (BRS/ LVE, Laurel, MD). Within the sound attenuation chamber was a smallanimal operant chamber (BRS/LVE) in which the rats were kept during conditioning. One wall of the operant chamber was fitted with two speakers that independently produce tones of up to $130 \mathrm{~dB}$ sound pressure level (SPL), with a frequency range of $\sim 1000-9000 \mathrm{~Hz}$. The back wall of the sound attenuating chamber was equipped with a small light. The electrode leads from the rat's head stage were connected to peripheral equipment and a Pentium computer. Computer software controlled the delivery of stimuli and the recording of eyelid EMG activity. One circuit permitted the delivery of a shock stimulus through a stimulus isolator (model number 365A; World Precision Instruments, Sarasota, FL). EMG activity was recorded differentially, filtered, amplified, and integrated by equipment that was similar to that used in previous studies (Stanton et al., 1992; Freeman et al., 1995a,b).

Conditioning procedure. The rat pups received training sessions that consisted of 100 trials each. Three sessions were run for each day of training at $\sim 4 \mathrm{hr}$ intervals. During the first training session, the rats were given unpaired presentations of a tone conditioned stimulus (CS) (2.0 $\mathrm{kHz}, 300 \mathrm{msec}, 85 \mathrm{~dB}$ SPL) and a periorbital shock unconditioned stimulus $(10 \mathrm{msec}, 4 \mathrm{~mA})$. The rats were then given five training sessions, which consisted of paired presentations of the tone conditioned stimulus and the shock unconditioned stimulus. In the paired condition, training sessions consisted of 10 blocks of 10 trials of delay conditioning. Of these, nine trials involve pairings of the auditory CS and the periorbital shock US, and one trial was a CS alone test trial. The CS coterminated with the $10 \mathrm{msec}$ US, yielding an interstimulus interval of $290 \mathrm{msec}$. Trials were separated by a variable intertrial interval that averaged $30 \mathrm{sec}$ (range of $18-42 \mathrm{sec}$ ). CRs were defined as responses that crossed a threshold of 0.4 units (amplified and integrated arbitrary units) above baseline during the CS period after $80 \mathrm{msec}$. Behavioral data were examined from computer records of EMG responses. Previous studies have shown that the paired training protocol used in this study established associative eye-blink CRs (Stanton et al., 1992; Freeman et al., 1993).

Stimulation procedure. A subset of rats at each age were given electrical stimulation through the recording electrodes. The stimulating current was applied at $100 \mathrm{~Hz}$ for $100 \mathrm{msec}$ at 5-250 $\mu \mathrm{A}$. Eyelid EMG responses were amplified, filtered, and recorded for off-line analysis. Movements of other body parts were observed visually.

Neuronal recording procedure. The activity of each microwire electrode was initially passed through a unity gain JFET preamplifier (NB Labs, Denison, TX). The outputs of the JFET preamplifier were fed into two eight-channel programmable amplifiers (Lynx-8; Neuralynx, Tucson, AZ), filtered between 300 and $3000 \mathrm{~Hz}$, and amplified at a gain of 10,000. The outputs of the amplifiers were fed into a computer-controlled acquisition system at $20 \mathrm{kHz} / \mathrm{channel}$ (Workbench-32; Datawave Technologies, Longmont, $\mathrm{CO}$ ) in which thresholding was used to detect and extract waveforms of units with signal-to-noise ratios of at least 2:1. The waveforms were saved as separate 32 point data chunks. Two voltage thresholds were used. Waveforms that crossed the lower threshold but did not cross the upper threshold within the 32 sample points were recorded on computer disk. The multiple unit records were then separated using custom software. This software displays all of the waveforms that were recorded during a particular data collection period (usually a training session). The user may examine any individual spike waveform that was recorded during the training session. A template-matching program was used to identify all of the spikes with similar waveform characteristics. This technique effectively isolated single units from multiunit records. However, it is possible that some of the unit recordings included the spikes of more than one neuron.

Data analysis. The behavioral data were examined for each training session. Repeated measures ANOVA was performed for the CR percentage, CR amplitude, unconditioned response (UR) percentage, and UR amplitude.

Peristimulus-time histograms of the firing rates of each unit were created for the entire period of the conditioning trials $(1 \mathrm{sec})$ for the pretraining, first, third, and fifth training sessions. The activity from the pre-CS baseline period was compared with three 97 msec intervals during the CS (not including the $10 \mathrm{msec}$ US period) and three $100 \mathrm{msec}$ intervals after the end of the US using the Wilcoxon rank test (Kubota et al., 1996; Freeman and Nicholson, 1999). In addition, group differences and changes across time in the data from all of the units were examined by repeated measures ANOVA. Separate analyses were conducted for the CS period and the post-US period. The CS and US periods were divided into $10 \mathrm{msec}$ intervals ( 29 for the CS and 30 for the US). The period during the presentation of the US was not analyzed because of the stimulation artifact. The data were normalized with respect to the baseline period by subtracting the mean baseline firing rate from the firing rate in each $10 \mathrm{msec}$ interval and dividing that value by the SD of the baseline. The normalized spike data were pooled for each rat. Significant interactions were examined by Tukey's honestly significant difference (HSD) test.

Histology. On the day after training, the rats were killed with a lethal injection of sodium pentobarbital $(90 \mathrm{mg} / \mathrm{kg})$ and transcardially perfused with $100 \mathrm{ml}$ of physiological saline, followed by $300 \mathrm{ml}$ of $3 \%$ formalin. After perfusion, the brains were post-fixed in the same fixative for a minimum of $24 \mathrm{hr}$ and subsequently sectioned at $50 \mu \mathrm{m}$ with a sliding microtome. Sections were then stained with cresyl violet. The locations of the recording electrodes were determined by examining serial sections.

\section{RESULTS}

\section{Behavior}

The rats trained on P24 and P25 exhibited significantly greater CR percentage and amplitude during sessions 3-5 than the rats that were trained on P17 and P18 (Fig. 1). The average onset latency of the CR was lower in the rats trained on P24-P25 than in the rats trained on P17-P18 during sessions 3-5. These data 


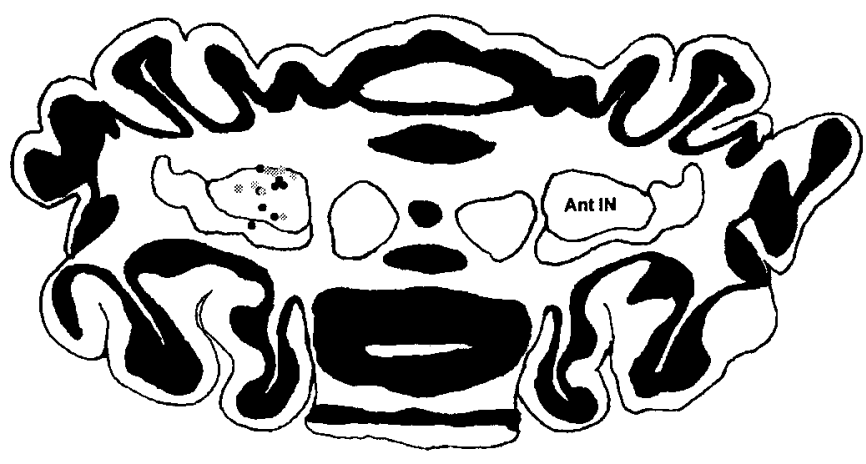

Figure 2. Drawing of a horizontal section of the rat brain with labels indicating the placement of the tips of the electrode bundles for rats trained on P17-P18 (black dots) or P24-P25 (gray dots). Ant IN, Anterior interpositus nucleus.

replicate the behavioral results of previous studies and indicate that the eye-blink conditioned response develops substantially between P17 and P24 (Stanton et al., 1992, 1998; Freeman et al., 1993, 1995a,b). There were no differences in the amplitude or percentage of the unconditioned response between the two age groups. This result indicates that the developmental change in conditioned response acquisition was not caused by a developmental change in performance of the eye-blink response.

The behavioral data were evaluated statistically by ANOVA. Analyses of both CR percentage and amplitude yielded significant interactions involving the group and training session factors (CR percentage, $F_{(5,65)}=7.25 ; p<0.001 ; \mathrm{CR}$ amplitude, $\left.F_{(5,65)}=3.80 ; p<0.005\right)$. Post hoc tests (Tukey's HSD) revealed a significantly greater percentage and amplitude of CRs for the rats trained on $\mathrm{P} 24-\mathrm{P} 25$ relative to the rats trained on $\mathrm{P} 17-\mathrm{P} 18$ during sessions $3-5$ (all comparisons, $p<0.05$ ). The onset latency of the CR was examined for CS alone test trials for only sessions 3-5 because most of the rats failed to produce CRs during test trials before session 3. The ANOVA revealed a significant effect of the group factor $\left(F_{(1,10)}=8.566 ; p<0.02\right)$, which was attributable to lower CR latencies in the rats trained on P24-P25 (means: P17-P18, 237 msec; P24-P25, $176.5 \mathrm{msec}$ ). There was a significant effect of the training session factor for the UR amplitude $\left(F_{(5,65)}=10.05 ; p<0.001\right)$ but no effects involving the group factor. The training session effect for the UR amplitude reflected an increase in UR amplitude across training sessions, which occurred in both groups.

\section{Electrode placement}

All of the units used in the data analysis of this experiment were recorded from the left interpositus region. Of the 16 electrode bundles, 15 were placed in the anterior nucleus, and one was placed in the posterior nucleus (Fig. 2).

\section{Interpositus neuronal activity}

The neuronal data were examined statistically with two types of analyses. First, the activity of each unit during the CS period and US period was compared with the pre-CS baseline activity using the Wilcoxon ranked test. The percentage of neurons that exhibited significant increases in activity was compared between groups by the $\chi^{2}$ test. Second, the normalized unit activity during the CS period and US period was subjected to ANOVA.

Figure 3 shows the activity of representative single units that were recorded during the fifth training session on P18 (left) and P25 (right). Figure 4 shows the percentage of neurons that exhib- ited significant increases in activity during the CS (top) and US (bottom) periods. A significantly greater percentage of neurons was excited during the first $100 \mathrm{msec}$ of the CS in the rats trained on $\mathrm{P} 24-\mathrm{P} 25$ relative to the rats trained on $\mathrm{P} 17-\mathrm{P} 18$ in the pretraining session $\left(\chi^{2}=4.47 ; p<0.04 ; 163\right.$ units $)$ and session 3 $\left(\chi^{2}=9.08 ; p<0.004 ; 166\right.$ units $)$. A developmental increase in neuronal activity was also observed during the last $100 \mathrm{msec}$ of the CS period in session $3\left(\chi^{2}=27.54 ; p<0.001 ; 166\right.$ units $)$ and session $5\left(\chi^{2}=8.89 ; p<0.004 ; 151\right.$ units $)$. One neuron in each age group exhibited a decrease in activity during the CS. During session 5 , the percentage of neurons that exhibited significantly greater CS period activity on trials with CRs when compared with trials with no CR was higher on P24-P25 than on P17-P18 $\left(\chi^{2}=9.64 ; p<0.003 ; 117\right.$ units) (Fig. 5). The age-related increase in the percentage of neurons with greater activity during trials with CRs indicates that the developmental change in neuronal activity was related to developmental changes in the production of CRs. This analysis could not be performed on the data from earlier sessions because most of the rats trained on P17 and P18 did not produce CRs before session 5 .

Similar results were found using ANOVA. The mean neuronal activity during the CS for both groups is displayed in Figure 6. There were significant effects involving the group factor for the pretraining session $\left(F_{(28,420)}=2.67 ; p<0.001 ; 163\right.$ units), session $1\left(F_{(28,392)}=2.82 ; p<0.001 ; 145\right.$ units $)$, session $3\left(F_{(1,14)}=8.16\right.$; $p<0.02 ; 166$ units), and session $5\left(F_{(1,14)}=4.73 ; p<0.05 ; 151\right.$ units). The group effects for sessions 3 and 5 were caused by an increase in neuronal activity during the CS from P17-P18 to P24-P25. Tukey's HSD tests of the activity during pretraining and session 1 revealed significantly greater activity in the P24P25 group during the first $10 \mathrm{msec}$ interval of the CS and greater activity in the P17-P18 group in the third $10 \mathrm{msec}$ interval of the CS (both comparisons, $p<0.05$ ). In addition, there was greater activity in the P24-P25 group during the second CS interval of the pretraining session and greater activity in the P17-P18 group in the fourth CS interval of session 1 (both comparisons, $p<$ $0.05)$. These results indicate that the onset of the initial response to the CS was delayed in the rats trained on P17-P18 relative to the onset of the initial response to the CS in the rats trained on $\mathrm{P} 24-\mathrm{P} 25$. The developmental differences in average neuronal activity were attributable to an age-related increase in the percentage of units with significantly increased activity during the CS and an age-related increase in the magnitude of activity of individual units. The units recorded from rats on P17-P18 that had a significant increase in activity typically exhibited only a modest increase above baseline relative to the units recorded on P24-P25.

The percentage of units that exhibited significant increases in activity after the US did not differ between groups. However, the ANOVA revealed significant effects involving the group factor for the pretraining session $\left(F_{(29,435)}=2.97 ; p<0.001\right)$, session 3 $\left(F_{(1,14)}=8.25 ; p<0.02\right)$, and session $5\left(F_{(1,14)}=5.94 ; p<0.03\right)$. The mean neuronal activity after the US for both groups is displayed in Figure 7. These effects were caused by greater activity after the US in the rats trained on $\mathrm{P} 24-\mathrm{P} 25$ relative to the activity in rats trained on P17-P18. Thus, although neurons in the interpositus nucleus responded after the US on P17-P18, the magnitude of the neuronal response was greater in rats trained on P24-P25. The developmental difference in US-related neuronal activity was evident during the unpaired pretraining session, which indicates that this developmental trend did not result from associative learning. 
PND17-18

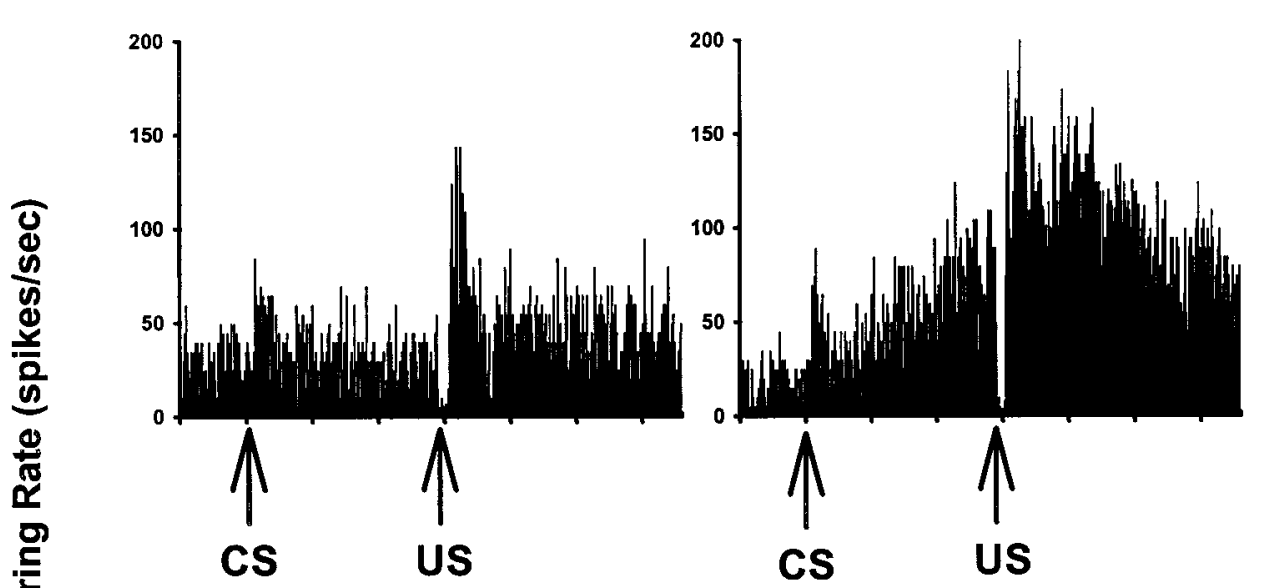

Figure 3. Mean firing rate (spikes per second) of representative units recorded in the cerebellar interpositus nucleus from rats trained on postnatal days 18 (left, PND1718) and 25 (right, PND24-25) during all 100 trials (top) and nine CS alone test trials (bottom) of training session 5. Arrows indicate the onset of the CS and US. The gap in unit activity during the US in the top panels is attributable to the stimulus artifact, which precluded recording unit activity.

The percentage of neurons that exhibited increased activity after the US was high in both groups relative to the results of previous studies that used adult rabbits (McCormick and Thompson, 1984; Berthier and Moore, 1986, 1990; Gould and Steinmetz, 1994, 1996). One reason for the relatively large-scale recruitment of cerebellar neurons by the US in the current study is that the magnitude of the US is much higher than in previous studies. The previous studies with rabbits used either an air puff US or a 0.1 msec shock US (McCormick and Thompson, 1984; Berthier and Moore, 1986, 1990; Gould and Steinmetz, 1994, 1996). The US in this study was far more intense, at $10.0 \mathrm{msec}$ and $4 \mathrm{~mA}$. The relatively intense US was required for establishing robust conditioning in rodents within five training sessions (Skelton, 1988; Freeman et al., 1993). However, the use of a relatively intense US probably recruits more afferent sensory fibers and results in a strong behavioral UR, which includes movement of multiple muscle groups. This issue was examined more directly by recording the activity of neurons in the interpositus nucleus in infant rats that were given presentations of the US at $0.5,1.0,2.0,3.0$, and $4.0 \mathrm{~mA}$ on either P17 or P24. The percentage of neurons that exhibited a significant increase in activity after the US increased as a function of US intensity. This result indicates that stimulus intensity is the primary factor that determines the percentage of interpositus neurons that become activated after the US.

\section{Interpositus stimulation}

Eyelid responses were elicited in rats from both age groups by stimulation of the interpositus nucleus. Current levels as low as 10
PND24-25

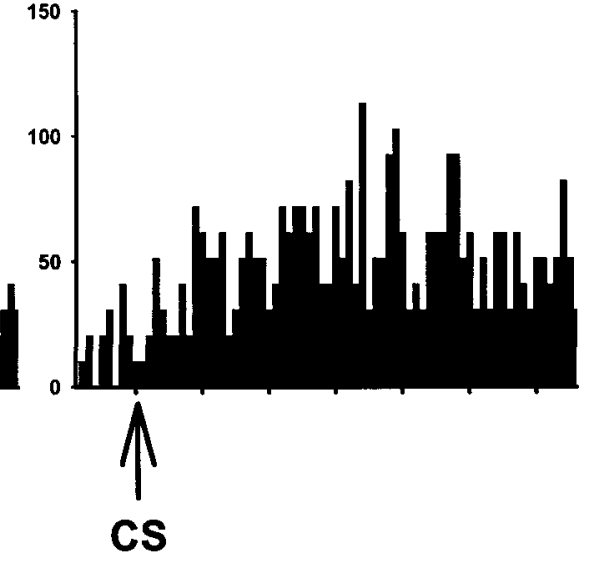

$\mu \mathrm{A}$ elicited eyelid EMG activity. As the current intensity was increased, the amplitude of the eyelid response increased and additional responses were elicited. Responses elicited by interpositus stimulation other than eyelid closure included movement of the facial musculature, nose, eye, jaw, head, and forepaw.

\section{DISCUSSION}

Developmental changes were observed in eye-blink conditioning and neuronal activity in the cerebellar interpositus nucleus. The age-related increase in the rate and magnitude of eye-blink conditioning replicated the results of previous studies (Stanton et al., 1992, 1998; Freeman et al., 1993, 1995a,b). Several significant changes in neuronal activity in the interpositus nucleus were observed. First, there was an age-related decrease in the latency of the initial response of neurons to the onset of the CS. This developmental trend was evident during the pretraining session and the first paired session (Fig. 6). The magnitude of the mean initial neuronal response to the CS did not change as a function of age and did not change as the CR emerged during training, which suggests that this initial neuronal response to the CS does not play a critical role in the ontogeny of eye-blink conditioning. Second, there was an age-related increase in the neuronal activity elicited during the last two-thirds of the CS period, just before the onset of the US. The developmental difference in the neuronal response at the end of the CS was evident during the third and fifth paired training sessions and corresponded to the developmental increase in CR percentage and amplitude (Fig. 6). Third, 
CS-Period 1

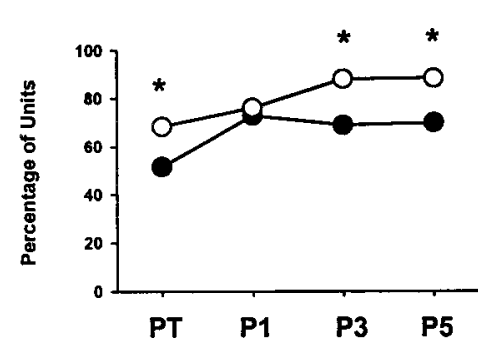

US-Period 1

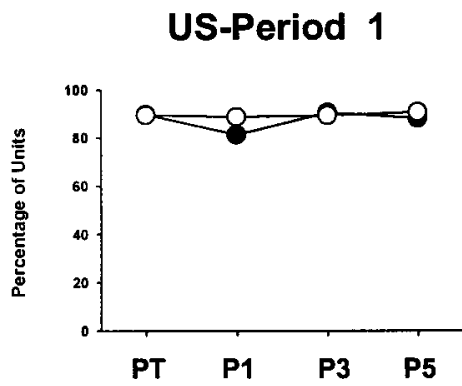

CS-Period 2

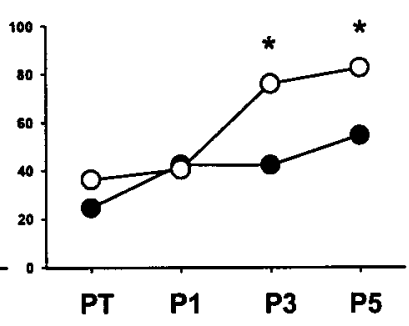

CS-Period 3

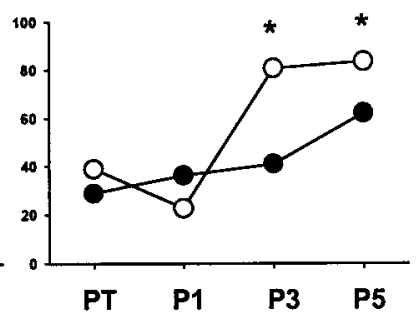

US-Period 2

US-Period 3
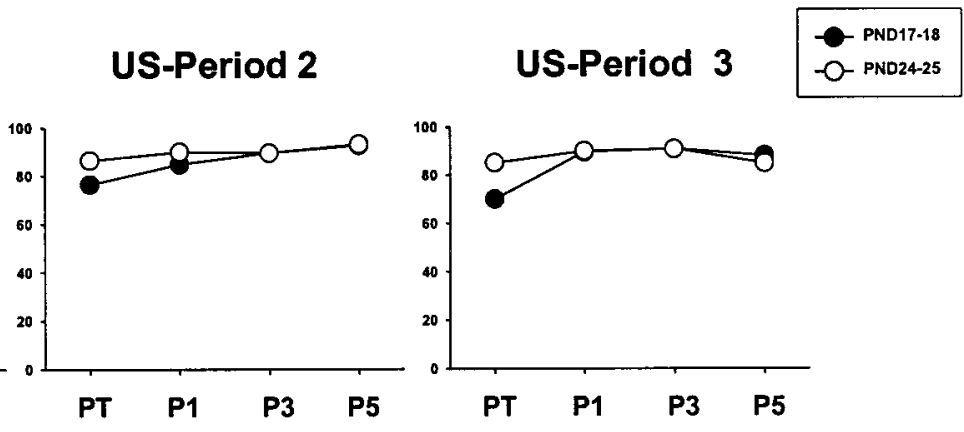

\section{Training Sessions}

Figure 4. Percentage of single units with significant increases in activity on P17-P18 (black circles) and P24-P25 (white circles) during the first, second, and third CS periods (top) and first, second, and third US periods (bottom) in the pretraining session (PT) and paired sessions 1, 3, and 5 (* indicates significant group differences). PND, Postnatal day.

CR-Related Units

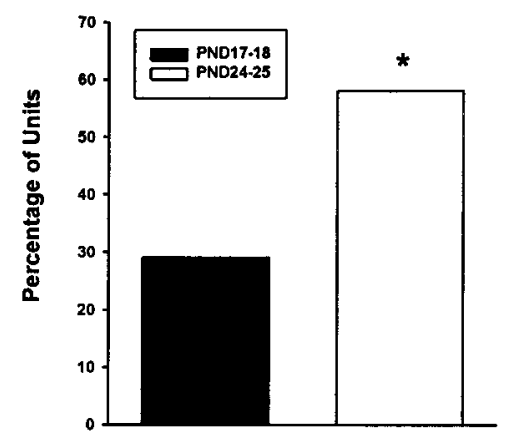

Figure 5. Percentage of neurons with significantly greater activity during trials with CRs relative to trials with no CRs on P17-P18 (black bar) and P24-P25 (white bar). PND, Postnatal day.

the magnitude of interpositus nucleus activity after the US increased with age (Fig. 7). The developmental change in neuronal activity after the US was evident before paired training. Each of the developmental changes in neuronal activity in the cerebellar interpositus nucleus may reflect functional changes in the eyeblink conditioning circuitry that significantly influence the ontogeny of learning.

Current models of the neural mechanisms of eye-blink conditioning assert that acquisition and maintenance of conditioned responses depend on the induction of neural plasticity in the cerebellum (Bartha et al., 1991; Bullock et al., 1994; Gluck et al., 1995; Raymond et al., 1996; Mauk, 1997; Mauk and Donegan, 1997; Moore and Choi, 1997). The developmental differences in eye-blink conditioning may reflect developmental changes in the induction of learning-specific plasticity in the cerebellar deep nuclei. According to this view, the rats trained on postnatal days 17 and 18 did not develop strong conditioned responding because their cerebellar neurons did not establish strong associative plasticity during training.

The developmental difference in the induction of learningspecific plasticity may be attributable to developmental changes in the afferents of the conditioned and unconditioned stimulus pathways to the cerebellum. It is well established that the rate and strength of learning is affected by the magnitude and timing of the conditioned and unconditioned stimuli (Gormezano et al., 1983). This presumably reflects the response of cerebellar neurons to afferent input from the stimulus neural pathways. Previous neurophysiological studies have shown significant developmental changes in the mossy and climbing fiber (the putative conditioned and unconditioned stimulus pathways, respectively) potentials and postsynaptic responses in the cerebellum (Crepel, 1971, 1974; Puro and Woodward, 1977a,b; Gardette et al., 1985a,b). It is not clear whether the developmental change in the cerebellar neuronal response to the stimuli is caused by developmental changes in presynaptic or postsynaptic processes. In either case, the weaker neuronal response after the unconditioned stimulus or the delayed onset of the CS-elicited neuronal response on postnatal day 17 , early in training, may affect the rate and strength of eye-blink conditioning by limiting the induction of cerebellar neuronal plasticity. Alternatively, there may be a developmental change in the mechanisms underlying the induction of cerebellar plasticity that are unrelated to processing of the stimuli and emerge in parallel with the developmental changes in the neuronal response to sensory inputs. In this case, the immature neuronal response of the afferent pathways would be sufficient for learning in a mature cerebellum, but the induction of plasticity is limited by develop- 
Figure 6. Mean neuronal activity (normalized to the pre-CS baseline activity) during the CS period for all the single units recorded from the cerebellar interpositus nucleus on P17-P18 (gray lines, PND17-18) and P24-P25 (black lines, PND24-25) in the pretraining session and paired sessions 1,3 , and 5 (* indicates significant bin differences between groups; + indicates group differences).
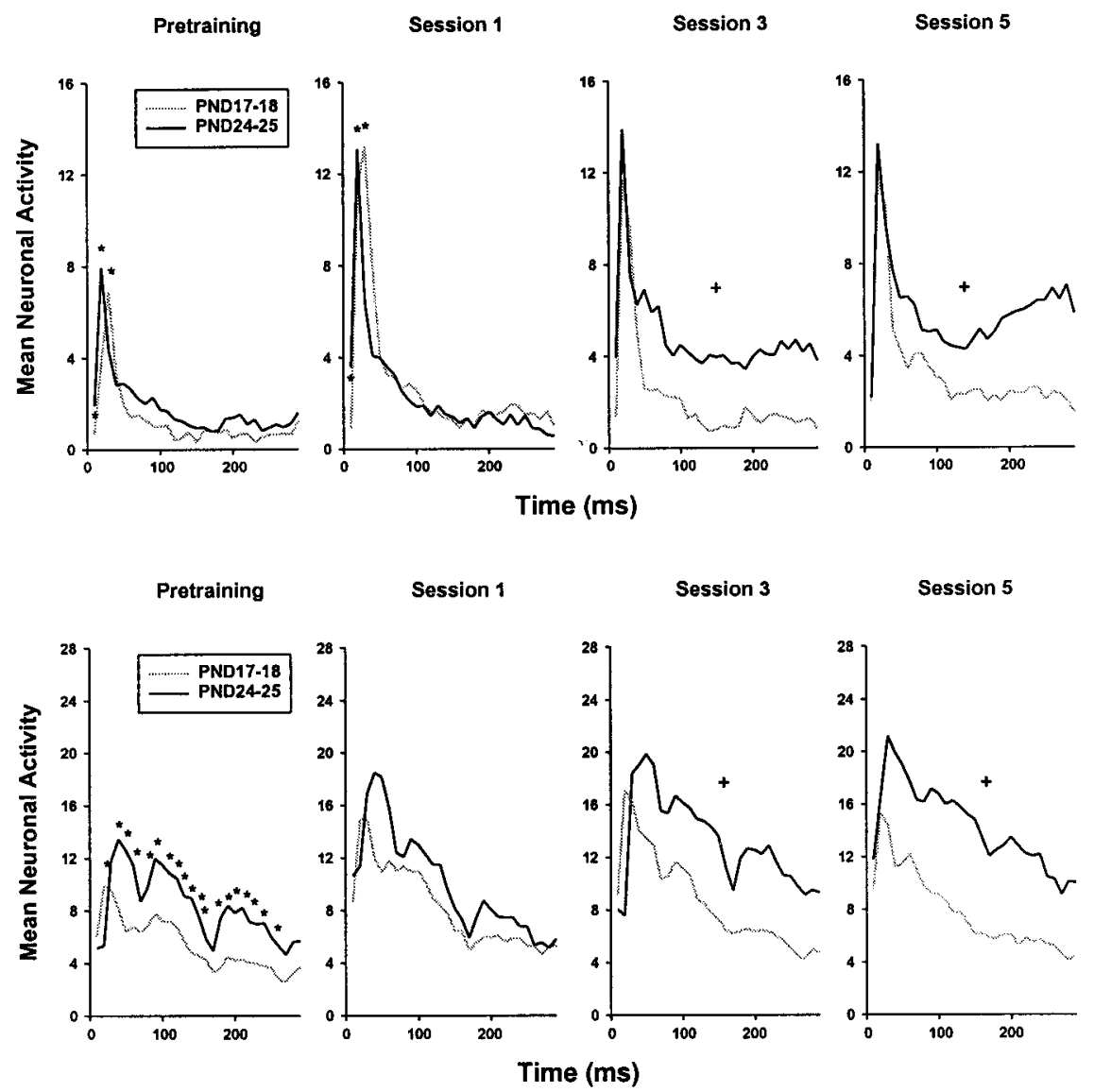

Figure 7. Mean neuronal activity (normalized to the pre-CS baseline activity) during the US period for all the single units recorded from the cerebellar interpositus nucleus on P17-P18 (gray lines, PND17-18) and P24-P25 (black lines, PND24-25) in the pretraining session and paired sessions 1,3 , and $5\left(^{*}\right.$ indicates significant bin differences between groups; + indicates group differences).

mental changes in the mechanisms of plasticity within cerebellar neurons.

It is important to note that the developmental changes in the responsiveness of cerebellar neurons to the conditioned and unconditioned stimuli do not indicate that there are developmental changes in performance of the unconditioned response or in brainstem auditory function. In fact, our studies have demonstrated that there are no developmental changes in the unconditioned response or the startle response to the CS (Stanton et al., 1992, 1998; Freeman et al., 1993, 1995a,b). We hypothesize that developmental changes in the cerebellar neuronal response to the conditioned and unconditioned stimuli primarily influence the induction of learningspecific neuronal plasticity within the cerebellum.

Another potential developmental change in the mechanisms of eye-blink conditioning is maturation of the neural systems that are necessary for the expression of the conditioned response. A recent study by Stanton and colleagues (Stanton et al., 1998) showed that rats given eye-blink conditioning on postnatal day 17 showed a small amount of associative savings when tested on postnatal day 20. An interpretation of this finding is that plasticity was induced in the cerebellum on postnatal day 17 but could not be expressed behaviorally until postnatal day 20. A developmental change in the expression of the conditioned response could be related to maturation of the efferent projections of the cerebellum to brainstem motor nuclei that control the blink response (Stanton et al., 1998). If there are developmental changes in cerebellar efferent output, they are not absolute because it was possible to elicit eye-blinks in 17-d-old rats with low-intensity electrical stimulation. Moreover, the behavioral savings seen in the Stanton et al. (1998) study were not complete. These observations indicate that maturation of the neural systems that mediate expression of the conditioned response may be one of several factors that influence the ontogeny of eye-blink conditioning.

This study is the first step in an analysis of developmental changes in the neurophysiological mechanisms of eye-blink conditioning. The findings suggest that there are developmental changes in the conditioned and unconditioned stimulus pathways and the mechanisms that induce neuronal plasticity in the cerebellum. Any of these developmental processes, alone or in combination, could account for the ontogenetic emergence of the eye-blink conditioned response. At present, there is no direct evidence concerning developmental changes in the cellular mechanisms of learning-specific plasticity in the cerebellum. Studies are currently underway to investigate ontogenetic changes in the cellular mechanisms underlying neuronal plasticity in the cerebellum.

\section{REFERENCES}

Altman J (1982) Morphological development of the rat cerebellum and some of its mechanisms. In: The cerebellum: new vistas (Palay SL, Chan-Palay V, eds), pp 8-49. Berlin: Springer.

Anderson WA, Flumerfelt BA (1985) Purkinje cell growth beyond the twenty-third postnatal day. Dev Brain Res 17:195-200.

Bartha GT, Thompson RF, Gluck MA (1991) Sensorimotor learning and the cerebellum. In: Visual structures and integrated functions (Arbib ME, Ewert J, eds), pp 381-396. Berlin: Springer.

Berry M, Bradley P (1976) The growth of dendritic trees of Purkinje cells in the cerebellum of the rat. Brain Res 112:1-35.

Berthier NE, Moore JW (1986) Cerebellar Purkinje cell activity related to the classically conditioned nictitating membrane response. Exp Brain Res 63:341-350. 
Berthier NE, Moore JW (1990) Activity of deep cerebellar nuclear cells during classical conditioning of nictitating membrane extension in rabbits. Exp Brain Res 83:44-54.

Bullock D, Fiala JC, Grossberg S (1994) A neural model of timed response learning in the cerebellum. Neural Networks 7:1101-1114.

Carew TJ (1989) Developmental assembly of learning in Aplysia. Trends Neurosci 12:389-394.

Clark GA, McCormick DA, Lavond DG, Thompson RF (1984) Effects of lesions of cerebellar nuclei on conditioned behavioral and hippocampal neuronal responses. Brain Res 291:125-136.

Crepel F (1971) Maturation of climbing fiber responses in the rat. Brain Res 35:272-276.

Crepel F (1972) Maturation of cerebellar Purkinje cells. I. Postnatal evolution of the Purkinje cell spontaneous firing in the rat. Exp Brain Res 14:463-479.

Crepel F (1974) Excitatory and inhibitory processes acting upon cerebellar Purkinje cells during maturation in the rat; influence of hypothyroidism. Exp Brain Res 20:403-420.

Crepel F, Penit-Soria J (1986) Inward rectification and low threshold calcium conductance in rat cerebellar Purkinje cells, an in vitro study. J Physiol (Lond) 372:1-23.

Crepel F, Mariani J, Delhaye-Bouchaud NJ (1976) Evidence for a multiple innervation of Purkinje cells by climbing fibers in the immature rat cerebellum. Neurobiology 7:567-578.

Diamond A (1990) The development and neural bases of memory functions as indexed by the $\mathrm{AB}$ and delayed response tasks in human infants and infant monkeys. Ann NY Acad Sci 608:267-317.

Freeman Jr JH, Nicholson DA (1999) Neuronal activity in the cerebellar interpositus and lateral pontine nuclei during inhibitory classical conditioning of the eyeblink response. Brain Res 833:225-233.

Freeman Jr JH, Stanton ME (1991) Fimbria-fornix transections disrupt the ontogeny of delayed alternation but not position discrimination in the rat. Behav Neurosci 105:386-395.

Freeman Jr JH, Spencer CO, Skelton RW, Stanton ME (1993) Ontogeny of eyeblink conditioning in the rat: effects of US intensity and interstimulus interval on delay conditioning. Psychobiology 21:233-242.

Freeman Jr JH, Barone Jr S, Stanton ME (1995a) Disruption of cerebellar maturation by an antimitotic agent impairs the ontogeny of eyeblink conditioning in rats. J Neurosci 15:7301-7314.

Freeman Jr JH, Carter CS, Stanton ME (1995b) Early cerebellar lesions impair eyeblink conditioning in developing rats: differential effects of unilateral lesions on postnatal day 10 or 20. Behav Neurosci 109:893-902.

Gardette R, Debono M, Dupont JL, Crepel F (1985a) Electrophysiological studies on the postnatal development of intracerebellar nuclei neurons in rat cerebellar slices maintained in vitro. I. Postsynaptic potentials. Dev Brain Res 19:47-55.

Gardette R, Debono M, Dupont JL, Crepel F (1985b) Electrophysiological studies on the postnatal development of intracerebellar nuclei neurons in rat cerebellar slices maintained in vitro. II. Membrane conductances. Dev Brain Res 20:97-106.

Gluck MA, Myers CE, Thompson RF (1995) A computational model of the cerebellum and motor- reflex conditioning. In: An introduction to neural and electronic networks (Zornetzer SE, Davis JL, Lau C, McKenna T, eds), pp 91-98. San Diego: Academic.

Gormezano I (1966) Classical conditioning. In: Experimental methods and instrumentation in psychology (Sidowski JB, ed), pp 385-420. New York: McGraw-Hill.

Gormezano I, Schneiderman N, Deaux EG, Fuentes I (1962) Nictitating membrane: classical conditioning and extinction in the albino rabbit. Science 138:33-34.

Gormezano I, Kehoe EJ, Marshall BS (1983) Twenty years of classical conditioning research with the rabbit. Prog Psychobiol Physiol Psychol 10:197-275.

Gould TJ, Steinmetz JE (1994) Multiple-unit activity from rabbit cerebellar cortex and interpositus nucleus during classical discrimination/ reversal eyelid conditioning. Brain Res 652:98-106.

Gould TJ, Steinmetz JE (1996) Changes in rabbit cerebellar cortical and interpositus nucleus activity during acquisition, extinction, and backward classical eyelid conditioning. Neurobiol Learn Mem 65:17-34.

Green RJ, Stanton ME (1989) Differential ontogeny of working memory and reference memory in the rat. Behav Neurosci 103:98-105.

Krupa DJ, Thompson JK, Thompson RF (1993) Localization of a memory trace in the mammalian brain. Science 260:989-991.
Kubota Y, Wolske M, Poremba A, Kang E, Gabriel M (1996) Stimulusrelated and movement-related single-unit activity in rabbit cingulate cortex and limbic thalamus during performance of discriminative avoidance behavior. Brain Res 721:22-38.

Lavond DG, Kim JJ, Thompson RF (1993) Mammalian brain substrates of aversive classical conditioning. Ann Rev Psychol 44:317-342.

Marcus EA, Carew TJ (1998) Developmental emergence of different forms of neuromodulation in Aplysia sensory neurons. Proc Natl Acad Sci USA 95:4726-4731.

Mauk MD (1997) Roles of cerebellar cortex and nuclei in motor learning: Contradictions or clues? Neuron 18:343-346.

Mauk MD, Donegan NH (1997) A model of Pavlovian eyelid conditioning based on the synaptic organization of the cerebellum. Learn Mem 3:130-158.

McCormick DA, Thompson RF (1984) Neuronal responses of the rabbit cerebellum during acquisition and performance of a classically conditioned nictitating membrane-eyelid response. J Neurosci 11:2811-2822.

McCormick DA, Clark GA, Lavond DG, Thompson RF (1982) Initial localization of the memory trace for a basic form of learning. Proc Natl Acad Sci USA 79:2731-2735.

Moore JW, Choi JS (1997) The TD model of classical conditioning: response topography and brain implementation. In: Neural network models of cognition: biobehavioral foundations. Advances in psychology (Donahoe JW, Dorsel VP, eds), pp 387-405. Amsterdam: Elsevier Science.

Nolen TG, Carew TJ (1988) The cellular analog of sensitization in Aplysia emerges at the same time in development as behavioral sensitization. J Neurosci 8:212-222.

Nolen TG, Marcus EA, Carew TJ (1987) Development of learning and memory in Aplysia. III. central neuronal correlates. J Neurosci 7:144-153.

Puro DG, Woodward DJ (1977a) Maturation of evoked climbing fiber input to rat cerebellar Purkinje cells (I.). Exp Brain Res 28:85-100.

Puro DG, Woodward DJ (1977b) Maturation of evoked mossy fiber input to rat cerebellar Purkinje cells (II.). Exp Brain Res 28:427-441.

Raymond JL, Lisberger SG, Mauk MD (1996) The cerebellum: a neuronal learning machine? Science 272:1126-1131.

Rudy JW (1992) Development of learning: from elemental to configural associative networks. In: Advances in infancy research (Rovee-Collier C, Lipsitt LP, eds), pp 247-289. Norwood, NJ: Ablex.

Schreurs BG, Sanchez-Andres JV, Alkon DL (1991) Learning-specific differences in Purkinje-cell dendrites of lobule HVI (lobulus simplex): intracellular recording in a rabbit cerebellar slice. Brain Res 548:18-22.

Schreurs BG, Tomsic D, Gusev PA, Alkon DL (1997) Dendritic excitability microzones and occluded long-term depression after classical conditioning of the rabbit's nictitating membrane response. J Neurophysiol 77:86-92.

Schreurs BG, Gusev PA, Tomsic D, Alkon DL, Shi T (1998) Intracellular correlates of acquisition and long-term memory of classical conditioning in Purkinje cell dendrites in slices of rabbit cerebellar lobule HVI. J Neurosci 18:5498-5507.

Skelton RW (1988) Bilateral cerebellar lesions disrupt conditioned eyelid responses in unrestrained rats. Behav Neurosci 102:586-590.

Stanton ME, Freeman Jr JH (1994) Eyeblink conditioning in the infant rat: An animal model of learning in developmental neurotoxicology. Environ Health Perspect 102:131-139.

Stanton ME, Freeman Jr JH (1999) Developmental studies of eyeblink conditioning in a rat model. In: Eyeblink classical conditioning: animal (Woodruff-Pak DS, Steinmetz JE, eds). Amsterdam: Kluwer.

Stanton ME, Freeman Jr JH, Skelton RW (1992) Eyeblink conditioning in the developing rat. Behav Neurosci 106:657-665.

Stanton ME, Fox GD, Carter CS (1998) Ontogeny of the conditioned eyeblink response in rats: acquisition or expression? Neuropharmacology 37:623-632.

Steinmetz JE (1998) The localization of a simple type of learning and memory: the cerebellum and classical eyeblink conditioning. Curr Dir Psychol Sci 7:72-77.

Thompson RF, Krupa DJ (1994) Organization of memory traces in the mammalian brain. Ann Rev Neurosci 17:519-549.

Yeo CH, Hardiman MJ, Glickstein M (1985) Classical conditioning of the nictitating membrane response of the rabbit. I. Lesions of the cerebellar nuclei. Exp Brain Res 60:87-98. 